\title{
CORRESPONDENCE
}

\author{
Correspondents are asked to be briet
}

Breech Management with Fetal Blood Sampling

W. G. Mills, F.R.c.o.G.; D. J. S. Hunter, M.R.c.o.G.; P. Donnai, M.R.c.o.G., and

A. D. G. Nicholas, F.F.A. R.C.S. . . . . . . . 229

Congenital Malformations and their Control

H. A. Wendel, $M$ D..............230

Test of Sensitivity of Staphylococci to Methicillin

J. G. Kensit, M.B. and N. A. Simmons,

M.R.C.PATH. . . . . . . . . . . . . . 230

Chlorprothixene and Obstructive Jaundice

D. G. S. Ruddock and J. Hoenig, M.R.C.P... 231

Hodgkin's Disease: A Clue or a Fluke?

Jean M. C. Clark, M.B. .

Thiocyanate Metabolism in Human

Vitamin $B_{12}$ Deficiency

A. G. Freeman, F.R.C.P.

Special Risks in the N.H.S.

G. H. Hall, F.R.C.P.

$\ldots \ldots \ldots 232$

Fatal Injuries after Car/Lorry Collisions

C. J. Wicks, M.B.; F. Kellerman, M.D......232

Making Hospital Geriatrics Work

Eluned Woodford-Williams, F.R.C.P.; F. A.

Binks, M.D. ...................232

Sheep's Head as a Source of Orf Infection

J. Savage, M.D..............233
Aleutian Mink Disease

L. Herzberg, M.R.C.P.

Conscience of the Profession

A. J. Barson, M.D.

Side Effects of the Pill

Kathleen $M$. Huntington, $M$.

Anaesthesia by Acupuncture

M. A. E. Ramsay, F.F.A. R.C.S. .

Congenital Tuberculosis Successfully....233

D. C. Gordon-Nesbitt, M.R.C.S., and

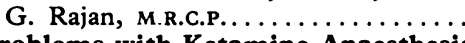

Problems with Ketamine Anaesthesia

Captain K. C. MacIntosh, M.B...........234

Drugs in Infertility

E. W. Barnes, M.R.C.P., and others.

Nutritional Value of School Meals

Susan M. Bateson, B.A., and M. C. Bateson,

M.R.C.P. $\ldots \ldots \ldots \ldots \ldots \ldots \ldots \ldots \ldots \ldots 234$

Referring Patients for Electrolysis

I. W. Caldwell, F.R.C.P..

Childhood Leukaemia and Pregnancy

Viraemia

C. M. D. Edmonds, D.P.H. . . . . . . 235

Measles Vaccination and Tuberculin Test

H. G. Calwell, M.D. .

Nitrazepam and the Elderly

F. O. Wells, M.R.C.G.P...........235
Hemifacial Spasm

R. J. V. Battle, F.R.c.s.; M. S. Harrison,

F.R.C.P.ED., F.R.C.S.ED. . . . . . . 235

Radiotherapy and Carcinoma of the Parotid

D. H. Patey, F.R.C.S............. 236

Dr. F. A. Cook's Diaries

G. Dove, M.B...................... 236

Hypotension and Methylmethacrylate

Cement

R. H. Ellis, F.F.A. R.C.S. . . . . . . . 236

ABO Blood Groups and Sex Ratio at Birth

T. M. Allan, M.B................ 236

Hazardous Wastes

P. J. Horsey, F.F.A. R.c.s. . . . . . . . . 237

Contraception and Infertility

H. P. Dunn, F.R.C.o.G. . . . . . . . . . . . . 237

Tubal Sterilization and its Reversal

E. A. Williams, F.R.C.o.G...........237

Consultant Negotiations

C. E. Astley, F.R.C.P. . . . . . . . . . . . 237

Future of the B.M.A.

R. A. Keable-Elliott, M.R.C.G.P.; P. M. Healy,

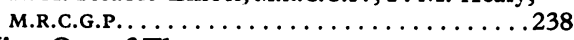

Nine Out of Three

R. V. Clark, F.R.C.S.ED............238

Fourteen Out of Seven

T. G. Reah, F.R.C.P...

\section{Breech Management with Fetal Blood Sampling}

SiR,-The admirable report of Dr. B. W. Eliot and Mr. J. G. Hill (23 December, p. 703) will be of great value to obstetricians working in units where the fetus can be monitored in labour by continuous cardiography and blood sampling. It will set a useful guide line for the sometimes difficult decision as to when labour should be curtailed by recourse to caesarean section.

For obstetric and midwifery staff in other units there will still be the traditional problem of how far the passage of meconium should be taken to indicate fetal asphyxia in cases of breech delivery. It is stated in the report that three out of 28 patients underwent section for fetal distress in the first stage of labour. It would be interesting to know the grounds for these decisions and also to have a much larger series with the incidence of visible meconium plotted against the fetal $\mathrm{pH}$ in the first stage of labour.

One further comment. It is accepted that serious intracranial haemorrhage is due to a combination of cerebral venous congestion and trauma to the after-coming head. The venous congestion may be due largely to asphyxia but it may be temporarily exacerbated by the delivery of the fetal body through a narrow pelvic outlet or a tight vaginal introitus. In these circumstances much of the fetal blood will have been "milked" upwards, increasing pressure in the superior vena cava and thus in the intracranial venous sinuses. Consequently, however urgently it may seem necessary to deliver the baby, it is even more essential to allow a brief interval after delivery of the fetal shoulders for the excess intracranial blood to flow back into the extremities. It is also advisable whenever possible to es- tablish fetal respiration, and thus to diminish the asphyxial element of cerebral congestion, before extracting the head with forceps.-I am, etc.,

Birmingham Maternity Hospita

WILFRID G. MILLS

SIR,-Dr. B. W. Eliot and Mr. J. G. Hill are to be congratulated on their most interesting article describing $\mathrm{pH}$ changes in the fetus during breech delivery (23 December, p. 703). It seems to me, however, that they failed to take into account the possibility that the fall in $\mathrm{pH}$ seen in the fetus during the second stage of labour in a breech delivery may in fact be due to placental bed retraction. If cord compression were responsible, I would expect the pH of the fetus to fall more rapidly towards the end of the delivery than at the beginning. The greatest retraction of the placental bed, however, will occur at the beginning of the delivery as the body of the fetus leaves the uterus and is delivered to the umbilicus, and I would therefore expect the greatest fall in $\mathrm{pH}$ to occur at this time, as the authors reported. From that point to the delivery of the head there will be only very slight further reduction in the placental bed area and one would therefore expect only a small further reduction in fetal pH. The fact that the greater the size of the fetus, the greater the fall in $\mathrm{pH}$ also suggests that reduction in placental bed area during delivery is the cause of the pH changes reported.

Dr. Eliot and Mr. Hill do, however, so rightly underline the very close monitoring of the breech delivery that is required, but unfortunately they do not describe the fetal heart rate patterns that were associated with the $\mathrm{pH}$ changes they observed. It would be most interesting to know whether the pH changes that indicated immediate intervention occurred without there being a similar warning from the fetal heart rate pattern -I am etc.,

David J. S. Hunter, Nuffield Department of Obstetrics and Gynaecology, University of Oxford

SIR,-We found the paper by Dr. B. W. Eliot and Mr. J. G. Hill (23 December, p. 703) concerning the changing fetal pH in the second stage of labour most interesting. However, the high incidence of fetal acidosis in this series prompts us to communicate in preliminary form the results we have obtained from a study of 93 breech deliveries by the vaginal route when epidural analgesia was used.

The umbilical vein $\mathrm{pH}$ was measured immediately after completion of the delivery in 42 cases and in five cases only was the cord $\mathrm{pH} 7 \cdot 20$ or below. The average length of labour and fetal weights were similar to those quoted in the above paper. It is our concern that compression of the buttock and the associated venous stasis may contribute to a falling buttock $\mathrm{pH}$ and not reliably reflect the fetal condition. In practice therefore we prefer to monitor the fetal heart continuously, using an electrode attached to the buttock, during breech deliveries. The observations of Shelley and Tipton ${ }^{1}$ with regard to the relationship between fetal heart rate and Apgar score seem to hold good for breech presentations as well.

Epidural analgesia, although of controversial value in breech delivery, is in our experience of considerable help during 